\title{
Persistence of low drug treatment coverage for injection drug users in large US metropolitan areas
}

\author{
Barbara Tempalski', Charles M Cleland, Enrique R Pouget, Sudip Chatterjee, Samuel R Friedman
}

\begin{abstract}
Objectives: Injection drug users (IDUs) are at high risk for HIV, hepatitis, overdose and other harms. Greater drug treatment availability has been shown to reduce these harms among IDUs. Yet, little is known about changes in drug treatment availability for IDUs in the U.S. This paper investigates change in drug treatment coverage for IDUs in 90 metropolitan statistical areas (MSAs) during 1993-2002.

Methods: We define treatment coverage as the percent of IDUs who are in treatment. The number of IDUs in drug treatment is calculated from treatment entry data and treatment census data acquired from the Substance Abuse and Mental Health Service Administration, divided by our estimated number of IDUs in each MSA.

Results: Treatment coverage was low in 1993 (mean 6.7\%; median 6.0\%) and only increased to a mean of 8.3\% and median of $8.0 \%$ coverage in 2002.

Conclusions: Although some MSAs experienced increases in treatment coverage over time, overall levels of coverage were low. The persistence of low drug treatment coverage for IDUs represents a failure by the U.S. health care system to prevent avoidable harms and unnecessary deaths in this population. Policy makers should expand drug treatment for IDUs to reduce blood-borne infections and community harms associated with untreated injection drug use.
\end{abstract}

\section{Introduction}

The HIV/AIDS epidemic among injection drug users (IDUs) is a critically important public health issue in the United States (U.S.). Currently, IDUs are the third highest risk group for HIV infection [1]. The shared use of injection equipment can also transmit hepatitis B and $\mathrm{C}$ [2-6]. The IDU population further experiences high rates of fatal drug overdose, endocarditis, cellulitis, and abscesses [7-10]. Injection drug users experience poor health outcomes due to delayed access to effective treatment, lower adherence to care and treatment regimens, continuation of illicit drug use, depression and negative life events [11-15].

Additionally, IDUs who do not enter treatment are six times more likely to become infected with HIV than are IDUs who enter and remain in treatment [9]. Milloy and colleagues [15] reported that being unable to access treatment was independently associated with recent incarceration, daily use of heroin and borrowing used

\footnotetext{
* Correspondence: tempalski@ndri.org

National Development and Research Institutes, Inc., 71 West $23^{\text {rd }}$ Street, $8^{\text {th }} \mathrm{Fl}$, New York, NY 10010, USA
}

syringes. Wood and colleagues [16] concluded that IDUs' inability to access treatment was independently associated with syringe borrowing among HIV-negative IDUs at risk for HIV infection.

Thus, there is considerable evidence indicating that drug treatment for IDUs is effective in reducing these harms [14,17-25] and improving users' health outcomes [13,14,19,26-29]. Research on the effectiveness of drug treatment further indicates that increased length of time in treatment is associated with lower rates of needle sharing and HIV seropositivity $[17,21,18]$. Furthermore, many programs provide access to AIDS education and prevention programs, and HIV testing, and provide contacts with health care systems to those clients already infected with HIV $[13,30]$. The inclusion of AIDS education programs within treatment protocols is associated with increased knowledge of AIDS risks, and decreased drug use and sexual behaviors that put IDUs at risk for HIV infection and other STIs [21,25,26,29]. Treatment therefore has the potential to address a broad social and public health agenda valued in communities affected by IDU.

\section{() Biomed Central}


Research has further demonstrated that drug treatment, such as methadone maintenance treatment, is costeffective, and is a key component for supporting harm reduction efforts among IDUs. Pollack [31] for example, explores the cost-effectiveness of methadone maintenance as an HIV prevention strategy. Epidemiological models suggest that methadone treatment is cost-effective for reducing HIV incidence at an average cost of between $\$ 100,000$ and $\$ 300,000$ per infection averted. This research also concludes that methadone maintenance is most costeffective in reducing HIV prevalence when treatment reaches a large proportion of IDUs within a given community [31]. Lastly, according to a 1998 study by Harwood [32], the cost benefits of methadone maintenance treatment show that costs to society from criminal activities related to opioid use can run as high as four times more than the costs for methadone treatment.

Though a number of studies have demonstrated that drug treatment program are effective in reducing drug use and other harm among IDUs [21,33-38], relatively little research has been done on the extent to which IDUs are actually reached by drug treatment programs (i.e. drug treatment coverage). While there is no level of coverage that universally has been agreed upon in preventing HIV among IDUs [22], current levels of HIV services for IDUs vary substantially and are inadequate in preventing HIV transmission [23,24]. And, although $100 \%$ drug treatment coverage for IDUs should be the ultimate goal, it may be both unrealistic and impossible to attain, as not all IDUs want to be in treatment, and those with opioid dependence often have a high rate of relapse, cycling in and out of treatment programs.

For the purposes of this study, coverage is defined as the percentage of IDUs who are in drug treatment in a given time period. Treatments included in our coverage estimates are residential or ambulatory inpatient/outpatient care, detoxification services and methadone maintenance therapy at publicly- and privately-funded substance abuse agencies receiving public funds. These are facilities licensed, certified, or otherwise approved by State substance abuse agencies to provide substance abuse treatment.

In this study we extend the scope of an earlier crosssectional study on treatment coverage [39] to include longitudinal data, and we describe change in drug treatment coverage for IDUs during 1993-2002 in 90 metropolitan statistical areas (MSAs). [NOTE: This study considers data collected prior to the availability of buprenorphine and naltrexone in the U.S.] Research on treatment coverage can provide insight to public policy planners, treatment providers and harm reduction activists regarding geographic areas in need of drug treatment expansion.

\section{Methods and data \\ Overview}

We calculated treatment coverage rates using two data series from the Substance Abuse and Mental Health Service Administration (SAMHSA), and estimates of IDUs from previous research [40]. Below we describe each data series:

1) Proportion of treatment entrants who indicated that they injected substances intravenously in each MSA and year as reported by the Treatment Episode Data Set (TEDS) [41];

2) Total number of drug users in drug treatment as of October 1 of each year reported by the Uniform Facility Data Set (UFDS) for 1993, 1995, 1996-1998 and the National Survey of Substance Abuse Treatment Services (N-SSATS) for 2000 and 2002 [42];

3) Total number of IDUs in each MSA and year as reported by Brady and colleagues [40].

We determine changes in coverage within each MSA where treatment coverage values were regressed on calendar year.

\section{Unit of Analysis and Sample}

We studied 90 MSAs as defined by the US Census as of 1993 [43]. MSAs are defined as a set of contiguous counties that contain a central city of 50,000 people or more and form a socioeconomic unit determined according to commuting patterns and social and economic integration within the constituent counties.

Data

We define treatment coverage as the ratio of IDUs in treatment to IDUs in the MSA. Treatment coverage for IDUs is estimated using TEDS and UFDS/N-SSATS. Each of our data sets differs in counts of substance abuse treatment clients. TEDS counts each admission in a given year. Therefore, an individual admitted to treatment twice in a calendar year is counted as two admissions, which inflates annual treatment entries. In contrast, UFDS/N-SSATS is a one day census of treatment, but does not report on the route of administration. By multiplying the percent of entrants who are IDUs (from TEDS) by the UFDS/N-SSATS census total we can estimate the number of IDUs in treatment. The proportion of entrants who are IDUs is only biased to the extent that double-counting of entrants varies systematically by route of administration.

The TEDS data series identifies the number and attributes of clients who enter substance abuse treatment programs. From TEDS, we calculated the proportion of treatment entrants who reported they injected drugs as a mode of administration. Our second SAMHSA data source comes from the annual census of drug treatment 
facilities originally referred to as the Uniform Facility Data Set (UFDS) - but since renamed the National Survey of Substance Abuse Treatment Services (N-SSATS). UFDS/N-SSATS data measure client characteristics and use of privately- and publicly-funded substance abuse treatment programs in the U.S. on October 1 for each year. However, UFDS/N-SSATS data were unavailable for 1992, 1994, 1999, and 2001. As a result of this limited availability, our drug treatment estimates were only created for years where data were available. Thus, our final coverage estimates only include data for 1993, 1995, 1996-1998, 2000, and 2002.

\section{Calculating Number of IDUs}

Because estimation of the total numbers of injectors is discussed in detail elsewhere [40], it is described only briefly here. Brady and colleagues first estimated the number of IDUs in the US each year from 1992-2002 and then apportioned these estimates to MSAs using multiplier methods. Four different types of data indicating drug injection were used to allocate national annual totals to MSAs, creating four distinct series of estimates of the number of injectors in each MSA. These estimates rely on using (1) HIV counseling and testing data from the Centers for Disease Control (CDC); (2) SAMSHA's UFDS and TEDS data; (3) CDC's diagnoses of IDUs with HIV/AIDS; and (4) an estimate derived from published estimates of the number of injectors living in each MSA in 1992 [44] and in 1998 [45]. Each series was smoothed over time using loess regression and the mean value of the four component estimates was taken as the best estimate of IDUs for that MSA and year.

Brady results indicated that nationwide IDU prevalence was relatively stable from 1992 to 2002; with a decreasing average trend across the 96 MSAs, until 2000, after which there was a slight increase; and individual MSAs deviate considerably from the average trend of the 96 MSAs. IDU prevalence varied from 30 to 348 across MSAs (mean 126.9, standard deviation 65.3, median 106.6, interquartile range 78-162) in 1992 and from 37 to 336 across MSAs (mean 110.6, standard deviation 57.7, median 96.1, interquartile range 67-134) in 2002 [40].

In order to avoid circularity, the estimated numbers of IDUs in the population used in this study modify the Brady estimates so that they do not rely on data on the numbers of IDUs in drug treatment from SAMSHA.

\section{Calculating Drug Treatment Coverage Rates}

Treatment coverage calculation:

$$
A_{j t}=\left(\frac{B_{j t}}{C_{j t}}\right) *\left(\frac{D_{j t}}{E_{j t}}\right) * 100
$$

$A_{j t}=$ treatment coverage rate for an MSA $j$ in year $t$

$B_{j t}=$ number of IDUs entering drug treatment as reported by TEDS for an MSA $j$ in year $t$

$C_{j t}=$ number of IDUs and NIDUs entering drug treatment as reported by TEDS for an MSA $j$ in year $t$

$D_{j t}=$ number of drug users entering drug treatment reported by UFDS/N-SSATS for an MSA $j$ in year $t$

$E_{j t}=$ estimated number of IDUs for an MSA $j$ in year $t$

\section{Calculating Change in Drug Treatment Coverage Rates}

In order to use all of the available data to estimate change and test change for statistical significance within each MSA, MSA-specific treatment coverage values were regressed on calendar year. For each of these linear regression models, the coefficient for year and its standard error was multiplied by nine to represent the total model-predicted linear change in treatment coverage from 1993 to 2002. The regression coefficient for the effect of year within each MSA was tested for significance using a two-tailed $p<0.05$ criterion. Since our aim here was to estimate change in each MSA separately, we did not adjust significance levels for multiple testing.

\section{Results}

\section{Descriptive statistics}

Additional file 1: Appendix 1 presents data on treatment coverage for each MSA in 1993 and 2002 and on change in coverage over time. Coverage overall changed little from 1993 to 2002. Mean coverage was only 8.3\% (standard deviation $4.28 \%$; interquartile range $5.0 \%-11.0 \%$ ) in 2002 (Table 1), a slight increase from 6.7\% in 1993 (standard deviation 3.7\%; interquartile range 4.0\%-9.0\%). Median treatment coverage increased only from $6.0 \%$ in 1993 to $8.0 \%$ in 2002 .

\section{Linear Regression Estimates of Change Over time}

The regression estimates of change also depict slow growth in overall coverage during the study period $($ mean $=1.58 \%$; median $=1.37 \%$; standard deviation $3.43 \%$; interquartile range $-0.57 \%$ to $3.08 \%$ ).

Fifteen MSAs experienced statistically significant increases in treatment coverage; of those, seven experienced increases of less than 5\% (Atlanta, GA; Cleveland, $\mathrm{OH}$; Dayton-Springfield, OH; Grand Rapids-Muskegon, MI; Miami, FL; Rochester, NY; West Palm Beach, FL). Seven MSAs experienced significant increases of between 5\% and 10\% (Detroit, MI; El Paso, TX; Monmouth-Ocean, NJ; Nassau-Suffolk, NY; New York, NY; Newark, NJ; Wilmington-Newark, DE-MD), and one 
Table 1 Estimated drug treatment coverage rates (percent in treatment) among injection drug users in 90 large US MSAs, 1993-2002

\begin{tabular}{rrrrrrr}
\hline & Mean & Standard Deviation & Median & Interquartile Range & Minimum & Maximum \\
\hline Treatment Coverage & & & & & & \\
\hline 1993 & 6.72 & 3.67 & 6.00 & $4.00,9.00$ & 1.00 & 16.00 \\
\hline 1995 & 6.69 & 4.18 & 5.67 & $3.51,9.51$ & 0.86 & 20.68 \\
\hline 1996 & 6.65 & 4.04 & 5.03 & $3.42,9.62$ & 0.88 & 18.14 \\
\hline 1997 & 6.35 & 4.10 & 5.41 & $3.32,9.04$ & 0.09 & 20.73 \\
\hline 1998 & 7.73 & 5.28 & 6.54 & $3.64,11.04$ & 0.00 & 26.20 \\
\hline 2000 & 7.34 & 4.49 & 6.23 & $3.81,9.84$ & 0.43 & 23.78 \\
\hline 2002 & 8.27 & 4.28 & 8.00 & $5.00,11.00$ & 1.00 & 21.00 \\
\hline Changet+† & 1.58 & 3.43 & 1.37 & $-0.57,3.08$ & -9.44 & 10.65 \\
\hline
\end{tabular}

NOTE: All values are percentages

†† from 1993-2002 as predicted by linear regression model

MSA increased greater than 10\% (Albany-Schenectady, NY). Three MSAs exhibited a statistically significant decrease in coverage ranging between -3.9 to -7.1 (Tacoma, WA; Fresno, CA; Honolulu, HI). Fully $80 \%$ of MSAs $(\mathrm{N}=72)$ in the study experienced no statistically significant change in treatment coverage over time.

\section{Discussion}

The overall level of treatment coverage for IDUs in our 90 MSAs began low and remained low through the end of the study period. Our results indicate there was a slight increase in average drug treatment coverage from 6.7\% to 8.3\% across 90 MSAs from 1993 to 2002. Fifteen MSAs experienced statistically significant increases in treatment coverage. Of those, only eight MSAs experienced increases of $5 \%$ or more (and all increases were $<11 \%)$. Three MSAs exhibited a statistically significant decline in coverage. During this period, estimated treatment coverage in 72 MSAs did not change significantly over time.

Some of the statistically significant changes (e.g., Cleveland, $\mathrm{OH}$; Dayton-Springfield, $\mathrm{OH}$; Miami, FL) were small in size. The fact that Cleveland and other MSAs had significant increases $(<5 \%)$ while Jersey City and Providence-Fall River ( $>5 \%$ ) did not is due to differences in the standard variation. The authors note that several of the statistically significant increases are quite small in magnitude, but are otherwise statistically reliable with regard to treatment coverage change over time.

Although outpatient methadone maintenance has been shown to be an effective treatment modality for opioid dependent patients by 1997 , only $7 \%$ of all treatment facilities offered outpatient methadone treatment, representing approximately $14-15 \%$ of all clients in the treatment system. Of these, $30 \%$ of outpatient methadone maintenance facilities are private for-profit, $53 \%$ are private non-profit, and $18 \%$ are publicly owned [46].These figures remain unchanged in 2008 , with only $8 \%$ of all substance abuse treatment facilities offering some type of opioid replacement therapy, either methadone or buprenorphine [47].

The need for increased investment in drug abuse treatment programs was underscored in the 2008 National Survey on Drug Use and Health, where 3.0\% of the total population (i.e., 7.6 million persons aged 12 or older) were estimated to be in need of treatment for an illicit drug use problem. Of those individuals, 1.2 million or $0.5 \%$ of the total population received treatment yielding a $16 \%$ coverage rate for drug users overall. This contrasts with only $8 \%$ for IDUs. Thus, an estimated $2.5 \%$ of the population (6.4 million) in need of treatment for an illicit drug use problem did not receive treatment, a figure that remains unchanged since 2002 [48]. A greater investment in treatment will likely be needed to have a substantial impact on injection drug use and associated harms. Investment in drug treatment expansion should be viewed as sound public health policy.

\section{Limitations}

Certain limitations must be taken into account when interpreting data from TEDS and UFDS/N-SSATS. During our study period, SAMSHA eliminated questions from UFDS about the number of IDUs in treatment programs after 1998. We therefore multiplied the proportion of drug users entering treatment who inject drugs (from TEDS) in each MSA and year by the total number of drug users in treatment as reported by both UFDS/N-SSATS. Second, these data sets differ in what they count: TEDS counts each admission in a given year, so an individual who enters drug treatment twice or more in a year is counted as two or more independent cases. In contrast, UFDS/N-SSATS client count numbers are a point-prevalence survey-those in treatment on one specific day. It gives a snap-shot of what the substance abuse treatment system looks like on an 
average day. Consequently, if IDUs differ from nonIDUs in the ratio of admissions to those remaining in treatment, our estimates will be biased.

Additionally, change in our estimated numbers of IDUs in treatment in an MSA might in part result from change in which treatment facilities in an MSA respond to SAMSHA surveys. The survey response rate increased from $87 \%$ in 1995 to $96 \%$ in 2002 , producing an $11 \%$ increase in reported U.S. client totals from 1993-2002. SAMSHA attempts to obtain responses from all known treatment facilities, but the survey is voluntary and no adjustments for facility non-response are made. Thus, the estimated increases in treatment coverage may partially reflect changes in survey methodology.

Finally, IDUs estimates beyond 2002 are currently being updated and were not readily available for our coverage estimates. Thus, our data does not extend beyond 2002. Nevertheless, there is little evidence to suggest that the number of IDUs in MSAs and the number of IDUs in treatment among the MSAs has significantly changed since then.

\section{Conclusions}

The evidence in this paper clearly indicates the need to expand drug treatment for IDUs. Coverage may be even lower in non-metropolitan suburbs or rural areas, since they tend to have fewer available healthcare services.

Injection drug use poses serious public health challenges with respect to public policy. Low treatment coverage for IDUs may produce a high cost to society in terms of the spread of HIV, hepatitis B and C and other infectious diseases among injectors, their partners, and the broader community. Drug treatment such as methadone maintenance therapy can address a broad social and public health agenda valued in communities affected by IDU. The persistent low drug treatment coverage for IDUs represents a failure of the U.S. healthcare system to prevent avoidable harms and unnecessary deaths.

More research is needed to address what policy and structural changes affect variations and changes in treatment coverage - and, in particular, what combinations of factors lead to increases in treatment coverage. Such research can help public policy planners, treatment providers and harm reduction activists understand the barriers to expanded drug treatment for IDUs.

Coverage rates in U.S. MSAs during the study period are far below international standards. Some European Union (EU) countries maintain coverage levels of $60 \%$ or higher [49]. The World Health Organization [22] has set targets for universal access to HIV prevention, treatment and care for IDUs. Targets for treatment coverage for IDUs accessing opioid substitution therapy define " $<20 \%$ " as "low" and "> 40\%" as "high [22]." Switzerland, where opioid substitution therapy is freely available, has attained treatment coverage levels of up to $70 \%$ over time [50]. Treatment coverage rates in the EU and other countries (e.g. Australia, 50\%) are higher in comparison with U.S. Clearly, more funding for drug treatment services for IDUs is needed from U.S. government sources to increase the overall level of treatment coverage to a level comparable to what the EU and other countries attain. Reducing the harm associated with injection drug use and making drug treatment accessible and a high public health priority is sound public health and government policy.

\section{Additional material}

Additional file 1: Appendix 1. Distribution and Change in Estimated Drug Treatment Coverage Rates among Injection Drug Users (IDUs) 1993-2002

\section{Acknowledgements}

This project was supported by the National Institute of Drug Abuse (R01 DA13336; Community Vulnerability and Response to IDU-Related HIV). We kindly acknowledge from the Substance Abuse and Mental Health Services Administration, Dr. Cathie E. Alderks; Deborah Trunzo and Gerri ScottPinkney for their assistance. The authors also thank Mr. Lucas Wiessing from the European Monitoring Centre for Drugs and Drug Addiction in Lisbon, Portugal for his thoughtful discussion and knowledge regarding drug treatment coverage in the European Union and elsewhere.

\section{Authors' contributions}

BT was responsible for data acquisition, analysis, and interpretation; and the writing of the article. CMC contributed to the analysis and interpretation of the data; and the writing of the article. SRF contributed to the conception and design of the analysis and the writing. ERP contributed to the writing of the article. SC contributed to data acquisition. BT, CMC, SRF, ERP, and SC read and approved the final manuscript.

\section{Competing interests}

The authors declare that they have no competing interests.

Received: 6 April 2010 Accepted: 21 September 2010

Published: 21 September 2010

\section{References}

1. Centers for Disease Control and Prevention. US Department of Health and Human Services: HIV/AIDS Surveillance Report. 2007, 19, Accessed March 16, 2010.

2. Burt RD, Hagan H, Garfein RS, Sabin K, Weinbaum C, Thiede H: Trends in hepatitis $B$ virus, hepatitis $C$ virus, and human immunodeficiency virus prevalence, risk behaviors, and preventive measures among Seattle injection drug users aged 18-30 years, 1994-2004. Journal of Urban Health 2007, 84:436-454.

3. Vassilev ZP, Hagan H, Lyubenova A, Tomov N, Vasilev G, Krasteva D, Des Jarlais DC: Needle exchange use, sexual risk behaviour, and the prevalence of HIV, hepatitis B virus, and hepatitis $C$ virus infections among Bulgarian injection drug users. International Journal of STD and AIDS 2006, 17:621-626.

4. Edlin BR, Kresina TF, Raymond DB, Carden MR, Gourevitch MN, Rich JD, Cheever LW, Cargill VA: Overcoming barriers to prevention, care, and treatment of hepatitis $C$ in illicit drug users: A review. Clinical Infectious Diseases 2005, 40:S5, S276-85.

5. Hagan H, Pouget ER, Des Jarlais DC, Lelutiu-Weinberger C: Meta-regression of hepatitis $C$ virus infection in relation to time since onset of illicit drug injection: The influence of time and place. American Journal of Epidemiology 2008, 168:1099-1109. 
6. Vlahov D, Des Jarlais DC, Goosby E, Hollinger PC, Lurie PG, Shriver MD, Strathdee SA: Needle exchange programs for the prevention of human immuno-deficiency virus infection: Epidemiology and policy. American Journal of Epidemiology 2001, 154:S70-S77.

7. Cooper H, Brady J, Ciccarone D, Tempalski B, Gostnell K, Friedman SR: Suboxone and Rising Hospitalizations for Infective Endocarditis among Injection Drug Users in the USA: No Evidence of a Causal Link. Clinical Infectious Diseases 2008, 46:955-956.

8. Spijkerman IJ, van Ameijden EJ, Mientjes GH, Coutinho RA, van den Hoek A Human immunodeficiency virus infection and other risk factors for skin abscesses and endocarditis among injection drug users. Journal of Clinical Epidemiology 1996, 49:1149-1154.

9. Centers for Disease Control and Prevention: Unintentional opiate overdose deaths-King County, Washington, 1990-1999. Morbidity and Mortality Weekly Report 2000, 48:636-40.

10. Morgan O, Griffiths C, Hickman M: Association between availability of heroin and methadone and fatal poisoning in England and Wales 19932004. International Journal of Epidemiology 2006, 35:1579-1585.

11. Lert F, Kazatchkine MD: Antiretroviral HIV treatment and care for injecting drug users: An evidence-based overview. International Journal of Drug Policy 2007, 18:255-261

12. Flanigan TP, Mitty JA, Macalino GE: Directly Observed Therapy and Other Community-Based Efforts to Improve Adherence to HAART. Clinical Infectious Diseases 2004, 38:S5, S373-436.

13. Spire B, Lucas GM, Carrieri MP: Adherence to HIV treatment among IDUs and the role of opioid substitution treatment (OST). International Journal of Drug Policy 2007, 18:262-70.

14. Fischer B, Oviedo-Joekes E, Blanken P, Haasen C, Rehm J, Schechter MT, Strang J, Van den Brink W: Heroin-assisted Treatment (HAT) a Decade Later: A Brief Update on Science and Politics. Journal of Urban Health 2007, 84:552-562.

15. Milloy MJ, Kerr T, Zhang R, Tyndall M, Montaner J, Wood E: Inability to access addiction treatment and risk of HIV infection among injection drug users recruited from a supervised injection facility. Journal of Public Health 2009, Accessed June 18, 2010.

16. Wood E, Spittal P, Li K, Kerr T, Miller CL, Hogg RS, Montaner J, Schechter MT: Inability to Access Addiction Treatment and Risk of HIV Infection Among Injection Drug Users. Journal of Acquired Immune Deficiency Syndromes 2004, 36:750-754.

17. Friedman SR, Jose B, Deren S, Des Jarlais DC, Neaigus A, National AIDS Research Consortium: Risk factors for HIV seroconversion among out-oftreatment drug injectors in high- and low-seroprevalence cities. American Journal of Epidemiology 1995, 142:864-874.

18. Metzger D: Drug abuse treatment as AIDS prevention. Public Health Reports 1998, 113:97-106.

19. Carrieri MP, Amass L, Lucas GM, Vlahov D, Wodak A, Woody GE: Buprenorphine Use: The International Experience. Clinical Infectious Diseases 2006, 43:S4, S197-S215

20. Mattick RP, Breen C, Kimber J, Davoli M: Methadone maintenance therapy versus no opioid replacement therapy for opioid dependence Cochrane Review. The Cochrane Library 2002, 3.

21. Sorensen $\mathrm{JL}$, Copeland AL: Drug abuse treatment as an HIV prevention strategy: a review. Drug and Alcohol Dependence 2000, 59:17-31.

22. World Health Organization, United Nations Office on Drugs and Crime, Joint United Nations Programme on HIV/AIDS: Technical guide for countries to set targets for universal access to HIV prevention, treatment and care for injecting drug users. [http://www.unodc.org/ documents/hiv-aids/idu_target_setting_guide.pdf], Accessed March 1, 2010.

23. Mathers BM, Degenhardt $L$, Ali H, Wiessing L, Hickman M, Mattick RP, Myers B, Ambekar A, Strathdee SA: HIV prevention, treatment, and care services for people who inject drugs: a systematic review of global, regional, and national coverage. Lancet 2010, 375:1014-1028.

24. National Institute on Drug Abuse: Global Coverage of HIV Services for Injecting Drug Users Inadequate to Prevent HIV Transmission. NEWSSCAN: NIDA Addiction Research News 2010, Special.

25. Uhlmann S, Milloy MJ, Kerr T, Zhang R, Guillemi S, Marsh D, Hogg RS, Montaner JS, Wood E: Methadone maintenance therapy promotes initiation of antiretroviral therapy among injection drug users. Addiction 2010, 105:907-913.
26. van Beek I: Case study: Accessible primary health care-A foundation to improve health outcomes for people who inject drugs. International Journal of Drug Policy 2007, 18:329-332.

27. Altice FL, Sullivan LE, Smith-Rohrberg D, Basu S, Stancliff S, Eldred L: The potential role of buprenorphine in the treatment of opioid dependence in HIV-infected individuals and in HIV infection prevention. Clinical Infectious Diseases 2006, 43:S4, S178-83.

28. Camacho LM, Bartholomew NG, Joe GW, Cloud MA, Simpson DD: Gender, cocaine and during-treatment HIV risk reduction among injection opioid users in methadone maintenance. Drug and Alcohol Dependence 1996, 41:1-7.

29. Longshore D, Hsieh S: Drug abuse treatment and risky sex: evidence for a cumulative treatment effect? American Journal of Drug \& Alcohol Abuse 1998, 24:439-451.

30. Holtgrave DR, Qualls NL, Curran JW, Valdiserri RO, Guinan ME, Parra WC: An overview of the effectiveness and efficiency of HIV prevention programs. Public Health Reports 1995, 110:134-146.

31. Pollack H: Cost-effectiveness of methadone treatment as HIV prevention. National HIV Prevention Conference. (Abstract No. 598) Atlanta, Ga 1999.

32. Harwood H, Fountain D, Livermore G: The Economic Costs of Alcohol and Drug Abuse in the United States 1992. National Institutes on Drug Abuse Rockville, MD 1998

33. Rhodes T, Kimber J, Small W, Fitzgerald J, Kerr T, Hickman M, Holloway G: Public injecting and the need for 'safer environment interventions' in the reduction of drug-related harm. Addition 2006, 101:1384-1393.

34. World Health Organization: Effectiveness of drug dependence treatment in preventing HIV among injecting drug users: Evidence for action technical paper and policy brief. 2005, Accessed March 1, 2010.

35. Schumacher JE, Mennemeyer ST, Milby JB, Wallace D, Nolan K: Costs and Effectiveness of Substance Abuse Treatments for Homeless Persons. The Journal of Mental Health Policy and Economics 2002, 5:33-42.

36. Sindelar JL, Fiellin D: Innovations in Treatment for Drug Abuse. Annual Review of Public Health 2001, 22:249-72.

37. Simpson DD, Flynn PM: Drug Abuse Treatment Outcome Studies (DATOS): A national evaluation of treatment effectiveness. In Encyclopedia of Substance Abuse Prevention, Treatment, and Recovery. Edited by: Fisher G, Roget N. Thousand Oaks, CA: Sage Publishing; 2008:303-307.

38. Barnett PG, Hui SS: The cost-effectiveness of methadone maintenance. Mt Sinai Journal of Medicine 2000, 67:365-374

39. Friedman SR, Tempalski B, Brady J, Friedman JJ, Cooper H, Flom PL, McGrath MM, Gostnell K, Des Jarlais DC: Predictors of the degree of drug treatment coverage for injection drug users in 94 metropolitan areas in the United States. International Journal on Drug Policy 2007, 18:475-485.

40. Brady JE, Friedman SR, Cooper HLF, Flom PL, Tempalski B, Gostnell K: Estimating the prevalence of injection drug users in the US and in large US metropolitan areas from 1992-2002. Journal of Urban Health 2008, 85:323-351.

41. Department of Health and Human Services, Office of Applied Studies: Treatment Episode Data Set (TEDS) 1992-2002: [United States] [Computer file], ver. $2^{\text {nd }}$ ICPSR04431 version. Ann Arbor, MI: Synectics for Management Decisions, Incorporated. Inter-university Consortium for Political and Social Research 2006.

42. Department of Health and Human Services SAMHSA, Office of Applied Studies: National Survey of Substance Abuse Treatment Services (N-SSATS), 2000, 2002: [United States] [Computer file], ver. $3^{\text {rd }}$ ICPSR version. Ann Arbor, MI: Synectics for Management Decisions, Incorporated. Inter-university Consortium for Political and Social Research 2006.

43. Office of Management and Budget: Standards for defining metropolitan and micropolitan statistical areas. Federal Register 2000, 65:82228-82238.

44. Holmberg S: The estimated prevalence and incidence of HIV in 96 large U.S. metropolitan areas. American Journal of Public Health 1996, 86:642-654.

45. Friedman SR, Tempalski B, Cooper H, Perlis T, Keem M, Friedman R, Flom PL: Estimating numbers of injecting drug users in metropolitan areas for structural analyses of community vulnerability and for assessing relative degrees of service provision for injecting drug users. Journal of Urban Health 2004, 81:377-400.

46. Substance Abuse and Mental Health Services Administration: Results from the 2002 National Survey on Drug Use and Health: National Findings. Office of Applied Studies. (DHHS Publication No. SMA 03-3836, NHSDA Series H-22) Rockville, MD 2003. 
47. Substance Abuse and Mental Health Services Administration: The N-SSATS Report: Overview of Opioid Treatment Programs within the United States: 2008. Office of Applied Studies Rockville, MD 2010.

48. Substance Abuse and Mental Health Services Administration SAMHSA: Results from the 2008 National Survey on Drug Use and Health: National Findings. Office of Applied Studies, NSDUH Series H-36, HHS Publication No. SMA 09-4434 Rockville, MD 2009.

49. European Monitoring Centre for Drugs and Drug Addiction (EMCDDA): 2009 Annual Report on the State of the Drugs Problem in the European Union. Lisbon 2009, Accessed March 2, 2010.

50. Nordt C, Stohler R: Incidence of heroin use in Zurich, Switzerland: A treatment case registers analysis. Lancet 2006, 367:1830-34.

doi:10.1186/1747-597X-5-23

Cite this article as: Tempalski et al:: Persistence of low drug treatment coverage for injection drug users in large US metropolitan areas. Substance Abuse Treatment, Prevention, and Policy 2010 5:23.

\section{Submit your next manuscript to BioMed Central} and take full advantage of:

- Convenient online submission

- Thorough peer review

- No space constraints or color figure charges

- Immediate publication on acceptance

- Inclusion in PubMed, CAS, Scopus and Google Scholar

- Research which is freely available for redistribution

Submit your manuscript at www.biomedcentral.com/submit 